Thorax, 1981, 36, 315-318

\title{
Arteriovenous fistula of the thoracic aorta: report of a case presenting with superior vena caval obstruction
}

\author{
EULOGIO MARTINEZ, JOSE MELLER, MOACIR GODOY, \\ JOAO LOURENCO V HERRMANN, AND ENIO BUFFOLO
}

From the Division of Cardiology, Department of Medicine, Paulista School of Medicine, Sao Paulo, Brazil and the Division of Cardiology, Department of Medicine, The Mount Sinai School of Medicine of the City of New York, New York, USA

Injuries of the great vessels are frequently fatal. When death does not occur, the patient may present with massive haemorrhage, shock, or cardiac tamponade requiring urgent operation. ${ }^{1}$ If a major haemorrhage does not occur and the patient survives, complications such as false aneurysm, mediastinal or cervical haematoma, haemothorax, coma, hemiplegia, or arteriovenous fistula may appear. ${ }^{2}$ Arteriovenous fistula involving the aorta is an extremely rare complication of thoracic trauma. Of 7500 American casualties in South east Asia who suffered some type of vascular trauma, only $7 \%$ of the injuries resulted in arteriovenous fistulae and false aneurysms, none of them involving the thoracic aorta. ${ }^{3}$ of 400 major arterial injuries treated over 20 years at a Los Angeles hospital, only one patient developed a fistula involving the thoracic aorta. ${ }^{4} \mathrm{~A}$ few other reports of arteriovenous fistulae of the aortic arch, mostly due to stab wounds, have been published; most of these patients presented with cardiac enlargement and cardiac failure. ${ }^{5-16}$

We report a patient, who, as a result of a knife wound, developed a fistula between the ascending aorta and the innominate vein and presented weeks later with superior vena caval obstruction.

\section{Case report}

A 36-year-old man was admitted to Hospital São Paulo in Brazil because of increasing swelling of the neck and face. One month earlier he had been stabbed with a knife in his upper chest and had been admitted to a rural hospital for observation. At that time he was asymptomatic, his physical examination was reported as unremarkable, and a chest radiograph was reported as normal. After four days he was discharged. One week later he noted progressive swelling of the neck and face, and easy fatiguability. At the same time he became dyspnoeic on moderate exertion and began to have slight dysphagia for all types of food. Because of the progression of his symptoms, he was referred to the Hospital S^o Paılo. He denied weight loss or fever.

Address for reprint requests: Jose Meller, Cardiology Division, The Mount Sinai Medical Center, One Gustave L Levy Place New York, New York 10029, USA.
On physical examination he appeared acutely ill, pale, and mildly tachypnoeic, with a respiratory rate of 20 per minute. Temperature was $37^{\circ} \mathrm{C}$; pulse was 92 per minute, regular and bounding; blood pressure was $140 / 30-0 \mathrm{mmHg}$ in the left and $160 / 30-0 \mathrm{mmHg}$ in the right arm, without orthostatic changes. There was much swelling of the face, oedema of the neck and jugular venous distention up to the angle of the jaw with the patient sitting. A well-healed scar $2 \mathrm{~cm}$ in length was seen at the level of the left sternoclavicular joint. The lungs were clear. The point of maximum impulse of the heart was normally located, but appeared hyperdynamic. A continuous thrill was felt and a continuous murmur grade IV-V/VI was present over all the precordium, more pronounced in the upper parasternal areas. The heart sounds were normal and there were no added sounds. The rest of the examination was unremarkable.

The laboratory tests revealed a hematocrit of $34 \%$, haemoglobin $10.6 \mathrm{~g} / \mathrm{dl}$, WBC $7 \cdot 7 \times 10^{9} / 1$ with a normal differential count. The ESR was $44 \mathrm{~mm}$ in the first hour. Urinalysis, and routine blood chemical tests were normal. An electrocardiogram was normal. A chest radiograph revealed a normal sized heart, considerable widening of the upper mediastinum with a smooth mass at the level of the ascending aorta and normal pulmonary vasculature (fig 1).

Cardiac catheterisation was performed through the right arm. The mean pressure in the superior vena cava was $65 \mathrm{mmHg}$; this pressure tracing had striking vibratory artefacts. The catheter could be advanced from the superior vena cava into the right atrium without difficulty. The mean right atrial pressure was $8 \mathrm{mmHg}$. The right ventricular pressure was $22 / 8$ $\mathrm{mmHg}$ and the pulmonary artery pressure $22 / 12$ $\mathrm{mmHg}$. The mean pulmonary capillary wedge pressure was $11 \mathrm{mmHg}$. The aortic pressure was $160 /$ $40 \mathrm{mmHg}$ and the left ventricular pressure was 160 / $12 \mathrm{mmHg}$.

The oxygen saturation was $85 \%$ in the superior vena cava, $62 \%$ in the inferior vena cava, $70 \%$ in the right atrium, $71 \%$ in the right ventricle, $70 \%$ in the pulmonary artery, and $98 \%$ in the aorta.

An injection of contrast material into the superior vena cava showed a dilated vein with markedly tortuous and dilated tributary veins (fig 2). The material 

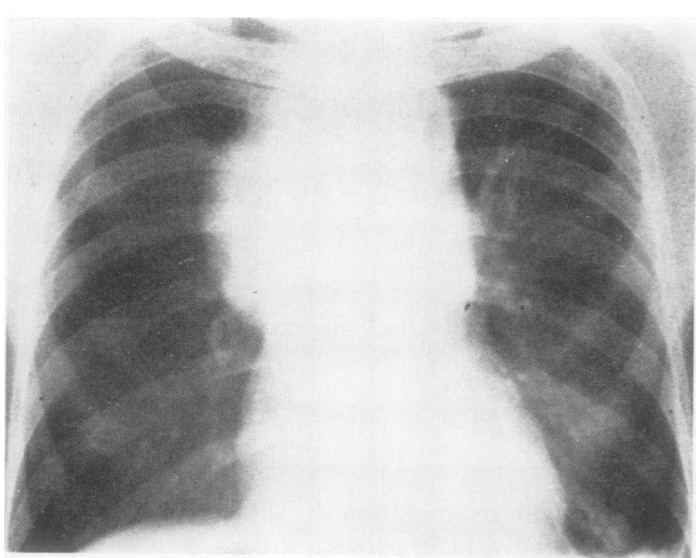

Fig 1 Chest radiograph at time of admission to hospital showing considerable widening of the upper mediastinum.

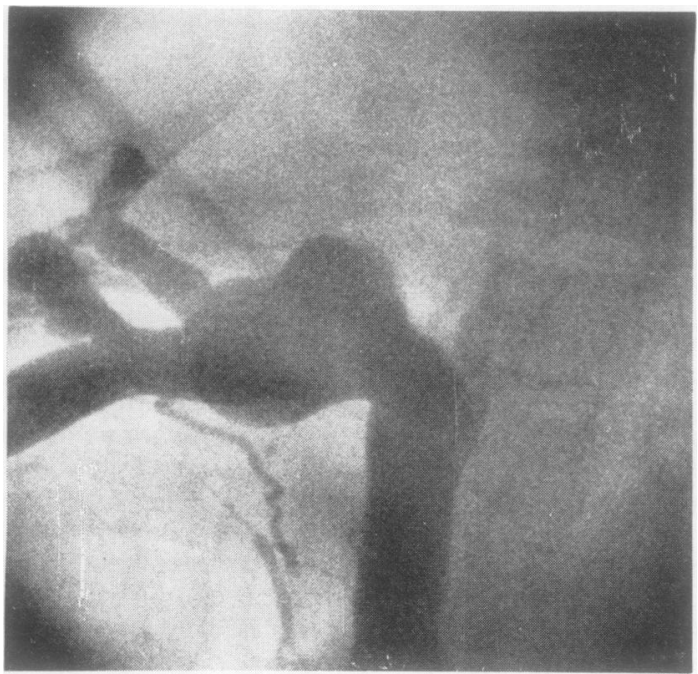

Fig 2 Superior vena cavogram demonstrating venous dilatation and tortuosity.

was prevented from reaching the right atrium by turbulent pulsatile non-opacified blood (fig 3). An injection into the right atrium showed normal right and left-sided chambers and normal contractility of the ventricles. An injection into the aorta showed posterior displacement of the ascending aorta, 1/4 aortic regurgitation into the left ventricle, extravasation of contrast material into a false aneurysm, and filling of the innominate vein (fig 4).

The patient was operated on the same day. Using cxtra-corporeal circulation via the femoral artery and vein the temperature was lowered to $20^{\circ} \mathrm{C}$. A median sternotomy was performed and under the sternum a grossly dilated innominate vein was found. A fistula between the aorta (at the level of the origin of the brachio ephalic branch anteriorly) and the innominate

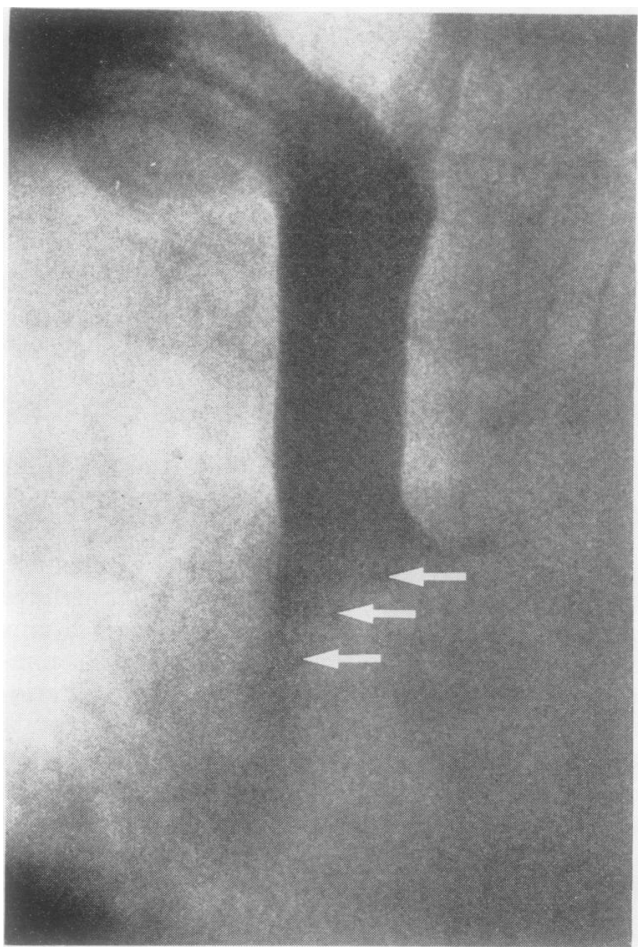

Fig 3 Superior vena cavogram demonstrating failure to opacify the right atrium because of turbulent pulsatile non-opacified blood (arrows).

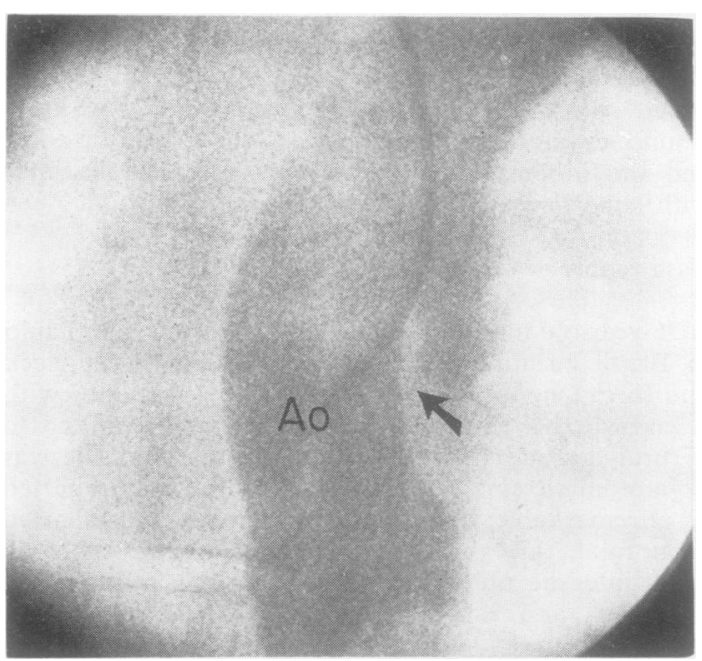

Fig 4 Aortogram showing extravasation of contrast material into a false aneurysm (arrow).

vein had resulted from a linear laceration $12 \mathrm{~mm}$ in length. The fistula was sutured, a false aneurysm between the aorta and the vein was resected and the vessels were reconstructed. 
The postoperative course was uncomplicated and the facial and cervical oedema disappeared within a week. At the time of discharge the patient was asymptomatic and had no heart murmur and a normal chest radiograph.

\section{Discussion}

Occlusion of the superior vena cava of ten produces a dramatic clinical syndrome, especially if it develops rapidly. Oedema of the head, neck, and upper extremities is seen, and the venous pressure in the upper extremities is commonly 30 to $50 \mathrm{~cm}$ of water. ${ }^{17}$ Compression of the superior vena cava by a malignant intrathoracic tumour is responsible for the vast majority of these cases. Bronchial carcinoma, especially one located in the right upper lobe, is the most common cause. Primary mediastinal tumours, lymphomas, and metastatic lesions are much less frequent. Mediastinal granulomas caused by histoplasmosis or actinomycosis, idiopathic mediastinal fibrosis, and aortic aneurysm are among numerous unusual causes. Our case illustrates yet another unusual cause of superior vena caval obstruction, probably from compression by the false aneurysm.

The clinical presentation of a patient with thoracic arteriovenous fistula depends on the site and size of the fistula and the presence of other injuries. ${ }^{18}$ The larger the fistula the earlier the symptoms of high output heart failure appear. Fistulae which are nearer to the heart have much greater blood flow and the haemodynamic alterations are consequently of greater magnitude. These fistulae are functionally similar to an intracardiac shunt in that only the pulmonary circuit is traversed by the excess flow. However, both ventricles participate in the increased volume workload, blood volume increases, venous pressure increases, and subsequently the ventricles dilate and finally fail. The cardiac enlargement initially is the result of dilatation rather than hypertrophy and may be quickly reversed after repair of the fistula. The low resistance escape for the aortic blood creates the peripheral physical findings classical of aortic regurgitation.

An arteriovenous fistula may develop a variable time after the trauma. ${ }^{19}$ The arterial laceration is commonly surrounded by a haematoma and thrombus formation seals the opening. Then a false aneurysm develops which may remain stable, thrombose, or enlarge. If the artery had become adherent to the scar of a similarly injured vein, the aneurysmal dilatation may rupture into the vein creating an arteriovenous fistula. In cur patient the absence of a heart murmur immediately after the stabbing suggests that the false aneurysm preceded the formation of the fistula.

The history of trauma and the presence of a continuous murmur and thrill facilitate the diagnosis of arteriovenous fistula. The reason for our patient developing superior vena caval obstruction rather than high output heart failure was probably the compression by the false aneurysm. It may have also been caused by the direction of the aortic blood flow into the innominate vein, preventing increased blood flow into the heart. Unfortunately cardiac outputs were not measured. However, there was no evidence of increased pulmonary blood flow on the chest radiograph or increased oxygen saturation in the rightsided cardiac chambers or pulmonary artery. Moreover, the cardiac chambers were all normal in size and all had normal pressures. Therefore, heart failure is not an obligatory component of a large thoracic arteriovenous fistula. This case is an example of a different clinical presentation; this complication should be recognised because successful surgical repair is possible.

\section{References}

1 Parmley LF, Mattingly TW, Manion WC, Jahnke EJ. Nonpenetrating traumatic injury of the aorta. Circulation 1958; 17:1086-101.

2 Symbas PN. Great vessels injury. Am Heart J 1977; 93:518-22.

3 Rich NM, Hobson RW, Collins GJ Jr. Traumatic arteriovenous fistulas and false aneurysms: a review of 558 lesions. Surgery 1975; 78:817-28.

4 Treiman RL, Cohen JL, Gaspard DJ, Gaspar MR. Early surgical repair of acute post-traumatic arteriovenous fistulas. Arch Surg 1971; 102:55961.

5 Proctor $\mathrm{WH} \mathrm{Jr}$. Arteriovenous fistula of the aortic arch. JAMA 1950; 144:818-9.

6 McCook WW. Arteriovenous fistula of the aortic arch. J Thorac Surg 1952; 23:299-302.

7 Sealy WC, Fawcett B. Arteriovenous fistula of ascending aorta and left innominate vein. Report of a case with successful surgical repair. Ann Surg 1955; 142:302-3.

8 Meredith JH, Bradshaw HH. Fistula betwen aorta and superior vena cava: report of traumatic case with surgical repair. J Thorac Surg 1957; 34: 278-80.

9 Conrad JK, Cartwright RS, Mostyn EM. Arteriovenous fistula of the aortic arch. Report of a case with hemodynamic data. N Engl J Med 1962; 267:15-9.

10 Tarlov E, Greenfield LJ. Post-traumatic aortic arch aneurysm with arteriovenous fistula to the innominate vein. $J$ Thorac Cardiovasc Surg 1968; 55:134-40.

11 Giraud RMA. Arteriovenous fistula of the aortic arch complicating stab wound of the neck. $S$ Afr Med J 1965; 39:474-6.

12 Symbas PN, Sehdeva JS. Penetrating wounds of the thoracic aorta. Ann Surg 1970; 171:441-50.

13 Heeckeren DW van, Botti RE, Cohen AM. Innominate arterial arteriovenous fistula complicating retrograde brachial arterial catheterization. Am J Cardiol 1979; 44:566-8.

14 Astolfi D, Di Carlo D, Di Eusanio G, Marcelletti C. Repair of traumatic aortic arch to innominate vein fistula under deep hypothermia and circulatory arrest. Thorax 1976; 31:753-6.

15 Beall AC, Roof WR, De Bakey ME. Successful surgical management of through-and-through stab 
wound of the aortic arch. Ann Surg 1962; 156: 823-6.

16 Quijano Pitman F, Plaza Celemin L, Naranjo Cordero J, Rey Dominguez L. Fistula arteriovenosa traumatica entre el cayado aortico y el tronco venoso braquiocefalico. Arch Inst Cardiol Mex 1969; 39:282-9.

17 Hurst JW, Logue RB eds. The heart, arteries, and veins. Fourth edition. New York: McGraw-Hill, 1978: 1854

18 Conn JH, Fain WR, Chavez CM. Traumatic aorto-caval fistulas. J Thorac Cardiovasc Surg $1967 ; 54: 880-5$.

19 Symbas PN. Traumatic injuries of the heart and great vessels. Chicago, Illinois: Charles $\mathrm{C}$ Thomas, 1972:126. 